\title{
CHARACTERISATION OF A MOBILE JAW CRUSHER FOR SMALL SCALE MINING AND CONSTRUCTION INDUSTRY
}

\author{
A. J. M. Itika \\ Department of Mining and Mineral Processing, University of Dar es Salaam, \\ P. O. Box 35131, Dar es Salaam, Tanzania, \\ E-mail:aitika@udsm.ac.tz
}

\begin{abstract}
A small jaw crusher with a crushing capacity of 1 ton per hour has been developed for use in the small scale mining and construction industry. A $3.68 \mathrm{~kW}$ air cooled diesel engine was installed to power the crusher. Laboratory and field test were conducted using limestone as feed material at different operating parameters. The analysis of the product from the crusher showed that at a constant jaw gap, coarser products were obtained when the rotary speed was varied from $220 \mathrm{rpm}$ to $300 \mathrm{rpm}$. With a jaw gap of $25 \mathrm{~mm}$, a higher cumulative undersize fraction was obtained at particle size $25 \mathrm{~mm}$. In contrast, at a jaw gap of $15 \mathrm{~mm}$, higher cumulative undersize fraction was obtained at particle size $15 \mathrm{~mm}$. With a feed size $80 \%$ passing $60 \mathrm{~mm}$, a finer product was obtained as compared to a feed $80 \%$ passing $120 \mathrm{~mm}$. The throughput of the machine increased from $0.4 \mathrm{ton} / \mathrm{hr}$ to $0.7 \mathrm{ton} / \mathrm{hr}$ when the speed was increased from $220 \mathrm{rpm}$ to $300 \mathrm{rpm}$. It was found that it is possible to select a combination of operating parameters to achieve a particular goal of operation.
\end{abstract}

(Key words: crushing, crusher, jaw crusher, size reduction, comminution, limestone crushing, small scale crushing machine)

\section{INTRODUCTION}

Crushing is the initial essential unit operation in mineral processing that helps reducing the size of materials to manageable sizes for further processing. Crushing is usually a dry process that is performed in several stages, with small reduction ratios ranging from three to six in each stage. The reduction ratio of a crushing stage can be defined as the ratio of maximum particle size entering to maximum particle size leaving the crusher. From the initial to the final stage particles may be reduced in size from over $1500 \mathrm{~mm}$ to $5-25 \mathrm{~mm}$ depending on the specific process requirements.

At the microscopic level, two conditions are known to be necessary for a particle to break. These are the strength and the energy conditions.

The strength condition demands that at the breakfront of the particle the forces binding its elementary components (molecular strength) must be exceeded by the applied stresses Schoenert [1991], Rumpf [1959]. However, in reality, it is found that the tensile stress at the breakfront is smaller by a factor of two to three power ten than the molecular strength of the particle at the breaking point. This has been explained by the notch effect caused by the presence of cracks and defects in the particle. This condition postulates the presence of a minimum crack whose size must increase to explain a further reduction in the yield stress of the particle compared to its molecular strength.

At the same time the energy condition requires that for a differential crack propagation, the elastic energy set free or released by the propagating breakage must equal or exceed the boundary surface energy to be built up. Griffith [1921] made this assumption and came up with the inequality

$-\frac{\partial U_{a}}{\partial l} \geq \frac{\partial S_{o}}{\partial l}$

where $U_{a}$ is the energy of deformation and $S_{o}$ is the boundary surface energy.

At a particular crack length known as Griffith length, the system is balanced. At higher crack 
length $I>I_{\text {griff }}$ the elastic energy term $-\partial U_{a} / \partial I$ grows and the crack propagates further.

\section{Mechanisms of Stressing}

Rumpf [1959] has defined three different mechanisms of stressing a particle. These are shown in Figure 1. A particle can be stressed between two surfaces, a process usually termed compression (Fig. 1a). In this category the shape of the stressing surface is immaterial allowing for consideration of even two sharp surfaces.

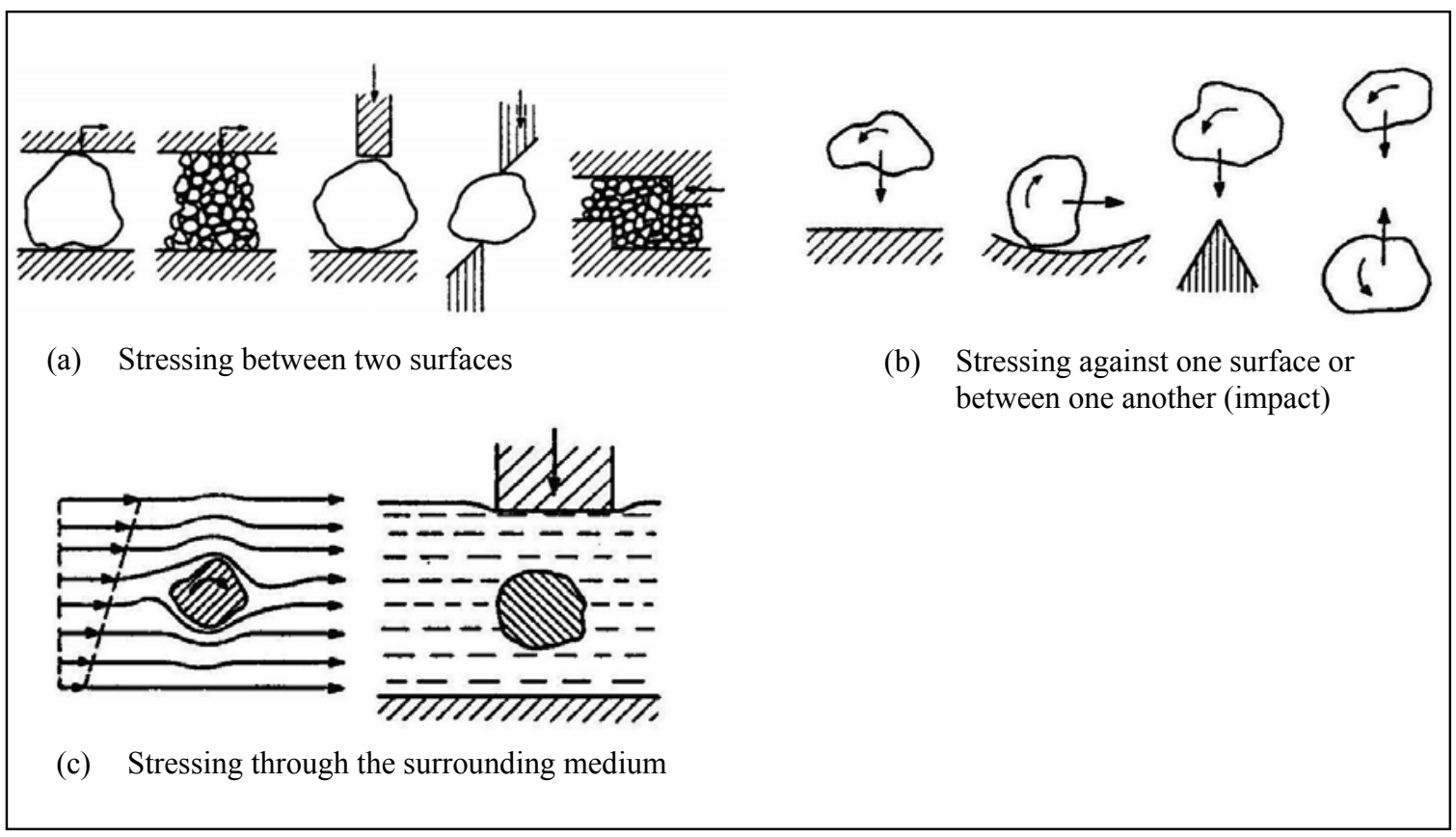

Figure 2: Stressing mechanisms of a particle (Rumpf 1959)

The particles can be stressed singly or collectively. Further, the particle can be stressed against a surface whereby either the particle or the surface is in motion (

Figure 2b). Alternatively, the particle can strike against another particle in a similar way. In this category, attrition of the particle usually accompanies the impact event especially because the particle is free to rotate.

The third stressing mechanism occurs when the particle finds itself surrounded by a medium ( Figure 2c). The stresses are induced due to relative motion of the fluid body or due to application of pressure waves on the fluid surface. This type of stressing can be important only in wet grinding.

\section{Crushing by Machines}

Over the years a number of machines have been developed that are applied for crushing materials to different sizes. The machines apply different stressing principles or a combination of them to effect the crushing. These include shear stress, compressive stress, bending stress, tensile stress, friction, impact, attrition etc. Among the machines that are applied for crushing are jaw crushers and cone crushers.

The energy required for size reduction in a machine is many times that actually required for the production of a new surface. The reason for this is that a lot of energy is being wasted in the friction of particles, in the deformation of the particles, as kinetic energy of the broken pieces, wear of the surfaces, sound and heat generation. 


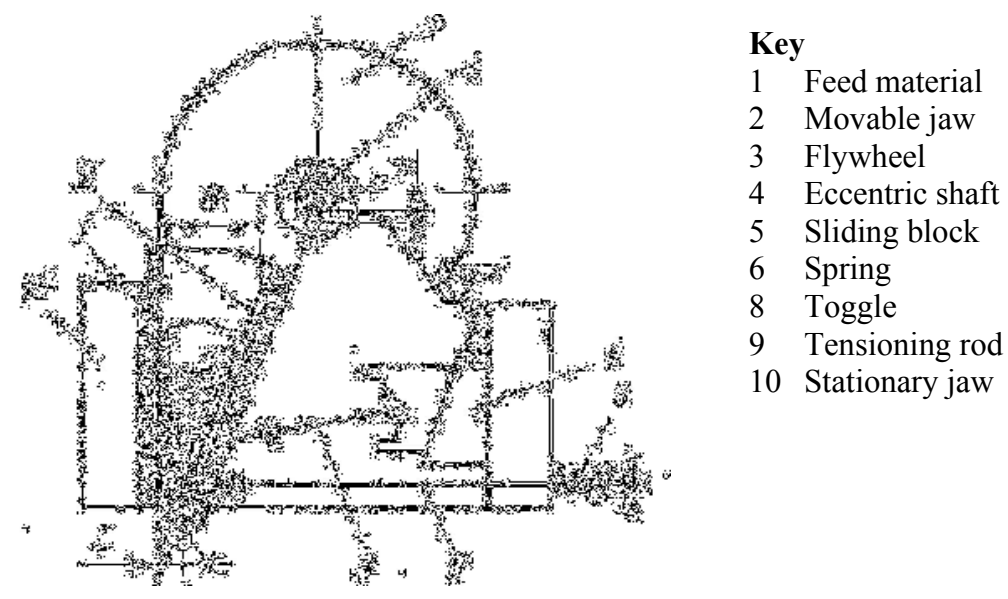

Figure 3: The jaw crusher showing the main parts

The jaw crusher consists basically of two jaws one movable and the other stationary. The movable jaw is pivoted at the lower end and is suspended on an eccentric shaft at the top. The jaw is slanted at an angle of about $24^{\circ}$ [Hoeffl 1986].

\section{The Design Calculations for the Jaw Crusher The angle of inclination}

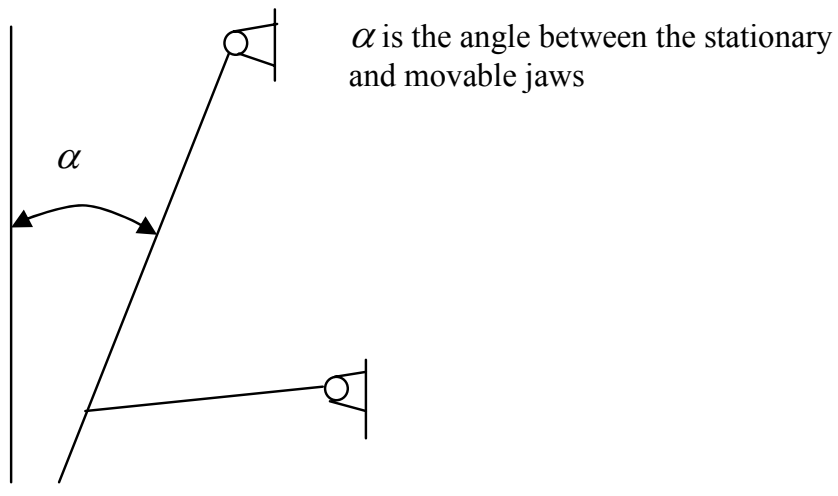

Figure 4: The angle of inclination of the jaw crusher

The maximum angle of inclination between the stationary and movable jaw can be estimated from:

$$
\tan \frac{\alpha}{2} \leq \mu
$$

where $\mu$ is the coefficient of friction
The eccentric motion of the shaft causes a helical motion of the movable jaw that continuously applies pressure at the feed material that is stepwise allowed to drop through the crushing chamber under gravity as it breaks. The bottom gap of the crusher " $t$ " determines the size of the product. The gap can be adjusted to suit the requirements of the user.

$\alpha$ is the angle between the stationary and movable jaws

If $\mu$ is assumed to be 0.3 then the angle $\alpha$ becomes about $33^{\circ}$. For design purposes a smaller value would be used.

The critical number of revolution of the shaft The critical number of revolution of the shaft may be calculated from the relation: 


$$
n_{G r}=\frac{1}{2} \sqrt{g \tan \frac{\alpha}{2 h}}
$$

where $g$ is the acceleration due to gravity, $h$ is the throw of the movable jaw (the bottom displacement of the jaw) and $\alpha$ is the angle of inclination of the movable jaw to the stationary jaw. In practice, the number of revolution of the drive shaft lies between 10 and $15 \%$ of the critical speed.

\section{The throughput}

An assumption is made that the crushed material moves in the crushing chamber like a prism. The throughput is therefore calculated from:

$$
\dot{V}=\operatorname{Vn} \varphi
$$

where $V$ is the volume of the falling prism, $n$ is the number of revolutions of the drive shaft and $\varphi$ is the voidage of the broken materials in the falling prism $(0.3-0.5)$
The volume of the falling prism can be calculated from:

$V=\frac{(2 s+h) b h}{2 \tan \alpha}$

Combining the two equations the throughput can be found from [Hoeffl 1986]:

$$
\dot{V}=\frac{\varphi n(s+h / 2) h b}{\tan \alpha} \mathrm{m}^{3} / \mathrm{s}
$$

To get the mass throughput one simply multiplies the above equation with the bulk density of the broken materials.

\section{EXPERIMENTAL WORK}

The crusher was developed and mounted on a special three wheeler bicycle as shown in Figure 5. The crusher was powered by a $3.5 \mathrm{HP}$ diesel engine.

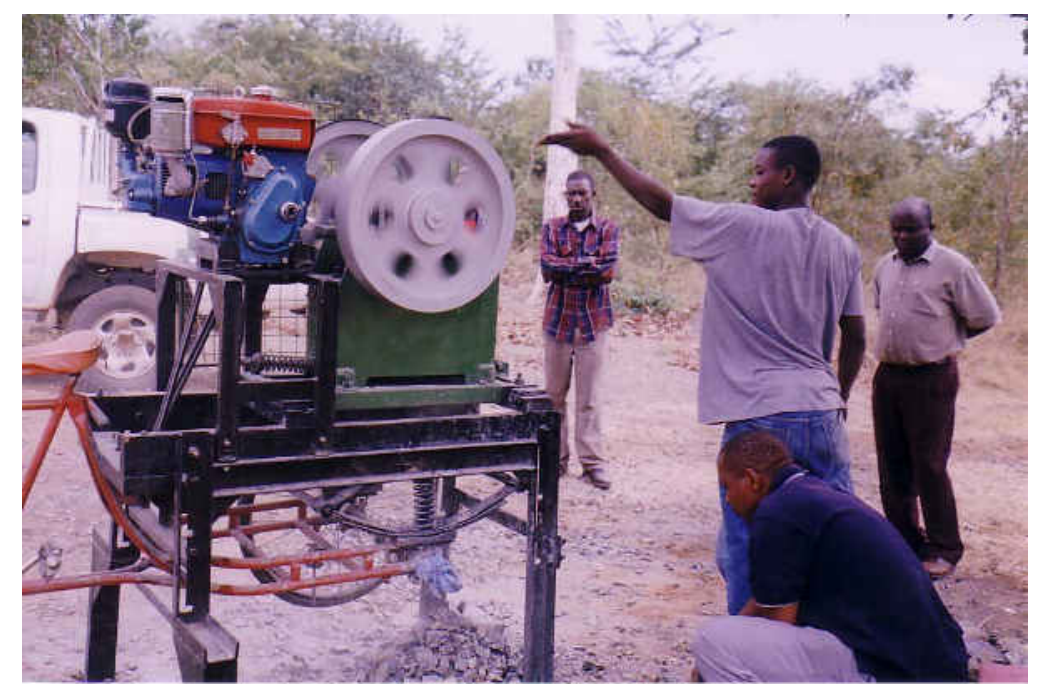

Figure 5: The small scale jaw crusher being tested

Various parameters including discharge gap, rotational speed of the drive shaft, rate of feed, feed size and nature of feed material were investigated on the crusher. One parameter was varied as the others were kept constant. Speed tests were conducted using a variable speed motor that was coupled to a gear box. Rotational speeds of the machine were monitored using tachometer verified with a stroboscope. The product size was analyzed using standard sieves. Each parameter was investigated at least three times to check the consistency and accuracy of the results obtained. Care was taken to ensure no product contamination from one experiment to the other. 


\section{DISCUSSION OF RESULTS}

\section{The Influence of the Number of Revolution on the Product}

Tests were conducted to investigate the influence of the number of revolution of the crusher at two different jaw gaps. Pre-crushed limestone of average size $12 \mathrm{~cm}$ obtained from Mtongani Quarry was used as feed material. A jaw gap of $15 \mathrm{~mm}$ was used in this set of experiments. Figure 6 shows the cumulative undersize fraction at revolution speeds between $220 \mathrm{rpm}$ and $300 \mathrm{rpm}$. From the graphs it can be seen that generally finer product was obtained at lower speeds of the machine. However, deviations from this trend have been observed at product sizes below $12.5 \mathrm{~mm}$. In that size range, finer product was obtained at a revolution speed of $260 \mathrm{rpm}$ as compared to the other speeds. Looking at the general trend at the revolution speed of $220 \mathrm{rpm}$, the cumulative fraction of $43 \%$ at the product size of $12.5 \mathrm{~mm}$ is an outlier. At the highest revolution speed of $300 \mathrm{rpm}$ coarser product is obtained throughout the considered size range.

At the revolution speed of $220 \mathrm{rpm}, 80 \%$ of the product was finer than $20 \mathrm{~mm}$. For the other revolution speeds of $240 \mathrm{rpm}, 260 \mathrm{rpm}$, and $300 \mathrm{rpm}, 80 \%$ of the products were finer than $22 \mathrm{~mm}, 23 \mathrm{~mm}$ and $25 \mathrm{~mm}$ respectively (Figure 6). Considering that the jaw gap was $15 \mathrm{~mm}$, it would be desirable to attain higher percentage of the product in the lower size range of around $15 \mathrm{~mm}$. Only $43-54 \%$ of the product is finer than $15 \mathrm{~mm}$ at the tested revolution speeds.

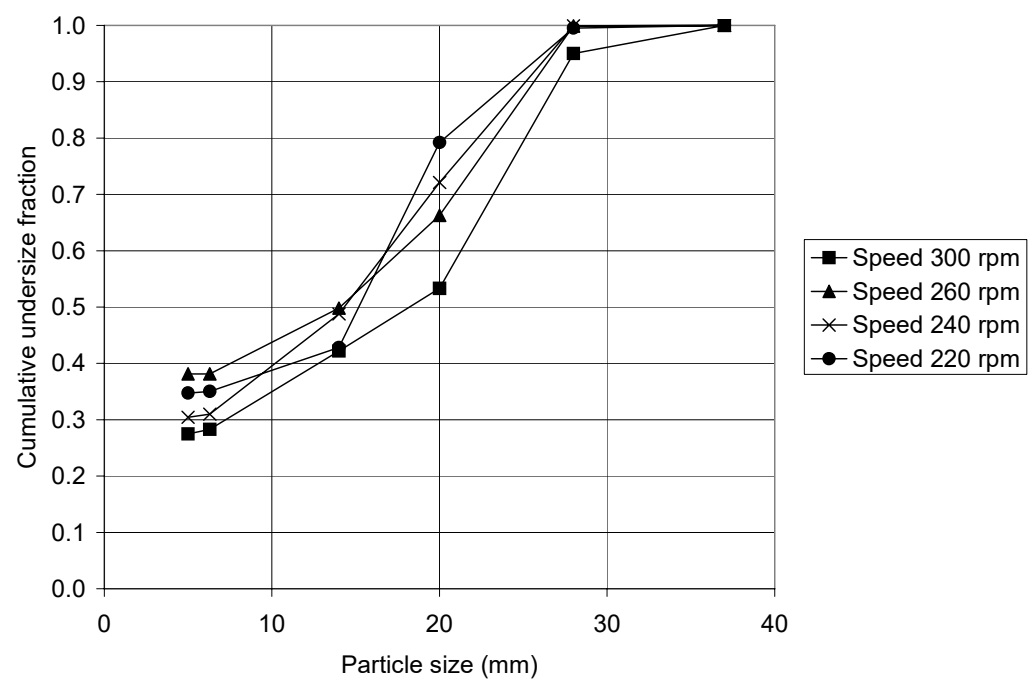

Figure 6: The influence of the number of revolution on the product at a jaw gap of $15 \mathrm{~mm}$.

Similarly, results were obtained at a jaw gap of $25 \mathrm{~mm}$ when the revolution speed of the machine was varied between $220 \mathrm{rpm}$ and 300 rpm. From Figure 7 it can be seen that finest product was obtained at a revolution speed of $220 \mathrm{rpm}$ having a mean particle size $\left(\mathrm{x}_{50}\right)$ of 11 $\mathrm{mm}$. At this revolution speed, $80 \%$ of the product had a size smaller than $21 \mathrm{~mm}$. 


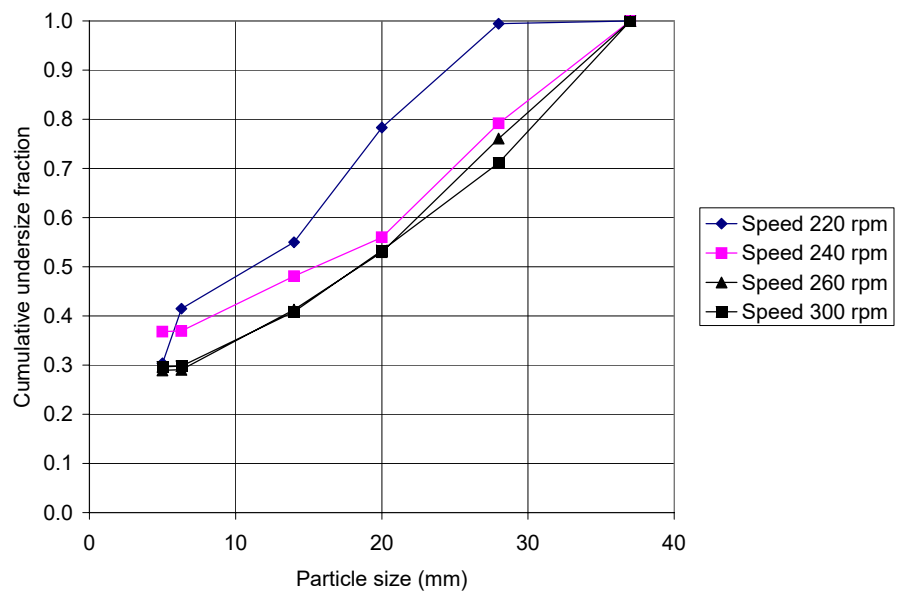

Figure 7: The influence of the number of revolution on the product at a jaw gap of $25 \mathrm{~mm}$.

At this jaw gap, the size distribution of the product at a speed of $240 \mathrm{rpm}, 260 \mathrm{rpm}$ and $300 \mathrm{rpm}$ are closer to each other as compared to that at a speed of $220 \mathrm{rpm}$. The mean particle sizes $\mathrm{x}_{50}$ of the products are respectively 15 $\mathrm{mm}, 18 \mathrm{~mm}$ and $18 \mathrm{~mm}$. Furthermore, the $80 \%$ passing product sizes were $28 \mathrm{~mm}, 30 \mathrm{~mm}$ and $31 \mathrm{~mm}$ at the revolution speeds of $240 \mathrm{rpm}, 260$ rpm and $300 \mathrm{rpm}$ respectively.
From these results, it is seen that at the revolution speed of $220 \mathrm{rpm}$, the change of jaw gap had practically no influence on the $80 \%$ passing product size. However at the other revolution speeds a marked change was observed as shown in

Table 9.

Table 9: The influence of jaw gap size and number of revolution on the product size ( $80 \%$ passing size)

\begin{tabular}{|l|c|c|c|}
\hline $\begin{array}{r}\text { Revolution } \\
\text { speed }\end{array}$ & 240 rpm & 260 rpm & 300 rpm \\
\hline Jaw gap & \multicolumn{3}{|c|}{$80 \%$ passing size $[\mathrm{mm}]$} \\
\hline $15 \mathrm{~mm}$ & 22 & 23 & 25 \\
\hline $25 \mathrm{~mm}$ & 28 & 30 & 31 \\
\hline
\end{tabular}

It is probable that at higher revolution speed the residence time of the particles is shortened resulting into coarser product. This overshadows any advantage that could have been exploited from faster stressing rate at higher speed.
The Influence of Revolution Speed on Throughput

It was observed from the experiments that the speed of the machine had an influence on the throughput. 


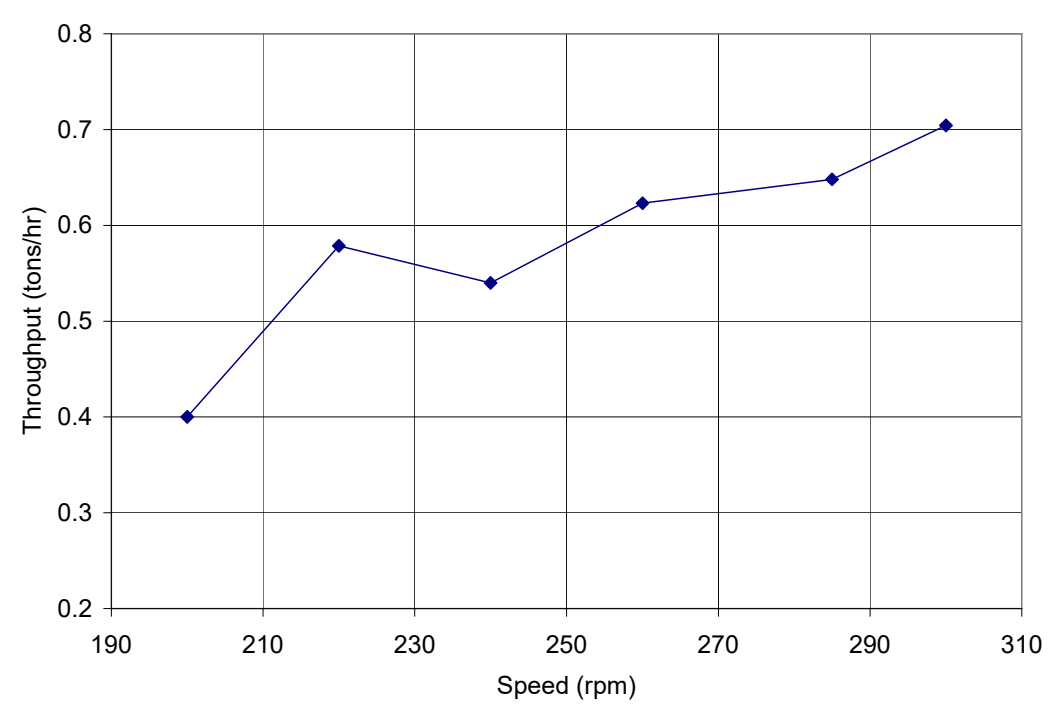

Figure 8: The dependence of the throughput on the speed at a jaw gap of $15 \mathrm{~mm}$

The general trend is increased throughputs at higher speeds of the crusher. The throughput was increased from $0.4 \mathrm{ton} / \mathrm{hr}$ at a speed of 200 $\mathrm{rpm}$ to $0.7 \mathrm{ton} / \mathrm{hr}$ at a speed of $300 \mathrm{rpm}$. This however, has the implication that the material has less residence time in the crushing chamber and therefore the product tends to be coarser (Figure 6, Figure 7).

\section{The Influence of Feed Size on the Product}

Feed sizes of $80 \%$ finer than $60 \mathrm{~mm}, 90 \mathrm{~mm}$, and $120 \mathrm{~mm}$ were used during the experiments. It was observed that there was insignificant change in product size when using feed of 60 and $90 \mathrm{~mm}$. However, coarser product was obtained when using feed material with size $120 \mathrm{~mm}$. The size of the $80 \%$ passing product increased with increasing feed size from $28 \mathrm{~mm}$ at feed size of $60 \mathrm{~mm}$ to $30.5 \mathrm{~mm}$ at feed size of $120 \mathrm{~mm}$. The product size variation seems to be more pronounced at the lower product size below $22 \mathrm{~mm}$. $40 \%$ of the product fall in this size range. There is insignificant difference in product size when using feed of $80 \%$ passing $60 \mathrm{~mm}$ and $90 \mathrm{~mm}$ (Figure 9).

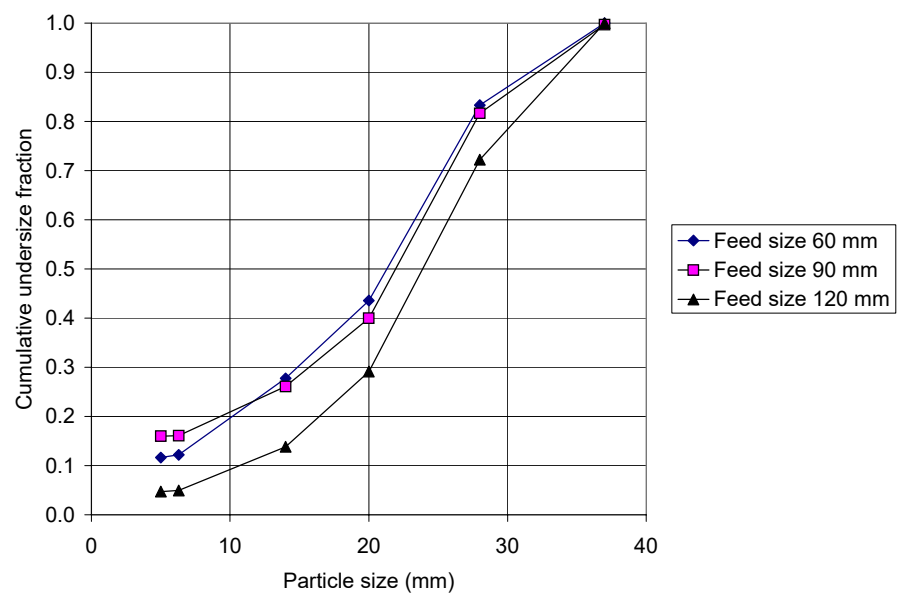

Figure 9: The influence of feed size on the product at a gap of $25 \mathrm{~mm}$ 
The Influence of Gap Size

The conducted experiments showed that there is a clear relationship between the jaw gap and the product size obtained. Generally finer product was obtained when the jaw gap was reduced (Figure 10).

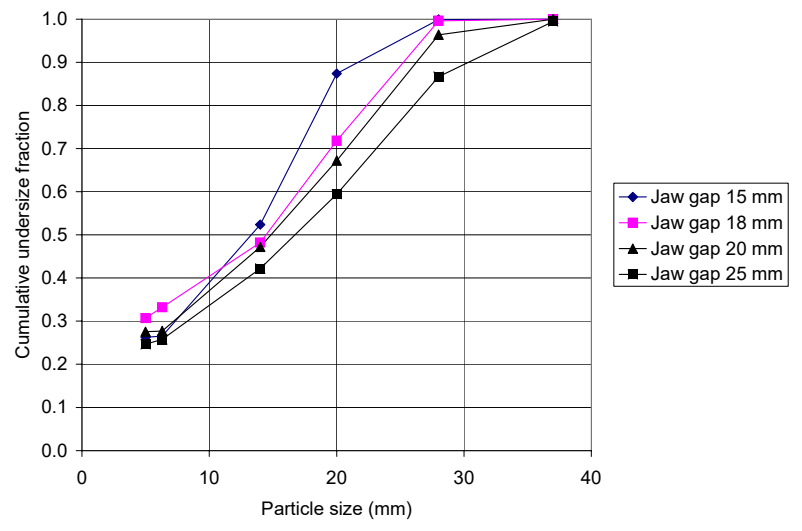

Figure 10: The variation of the product size distribution with the change in jaw gap

The product size seems to converge in the lower size range below $15 \mathrm{~mm}$. The product cumulative undersize fraction, at a particle size equal to the jaw gap, increased with increasing jaw gap (Table 2)

Table 10: Product cumulative undersize fraction at particles equal to the jaw gap

\begin{tabular}{|c|c|c|c|}
\hline S/No. & Jaw gap $[\mathrm{mm}]$ & Particle size $[\mathrm{mm}]$ & Cumulative undersize fraction \\
\hline 1 & 15 & 15 & 0.58 \\
\hline 2 & 18 & 18 & 0.63 \\
\hline 3 & 20 & 20 & 0.67 \\
\hline 4 & 25 & 25 & 0.76 \\
\hline
\end{tabular}

When the jaw gap of $15 \mathrm{~mm}$ was used, a cumulative undersize fraction of 0.58 was obtained for a particle size of $15 \mathrm{~mm}$. In comparison, when the jaw gap was $25 \mathrm{~mm}$, a cumulative undersize fraction of 0.76 was obtained for a particle size of $25 \mathrm{~mm}$. If we retain the definition of the product size as " $80 \%$ passing", then we may infer that the product size gets closer to the jaw gap with increasing jaw size.

\section{CONCLUSION}

The behaviour of the crusher varies with both operating and structural characteristics. These results have been based on limestone available in a location at Dar es Salaam. Material characteristics may have influence on the results obtained and therefore need to be considered when interpreting these results under different conditions. The behaviour of the crusher has been found to conform to general established knowledge in the area of comminution.

\section{ACKNOWLEDGEMENT}

The author is very grateful to the Private Sector Support Unit of the then Ministry of Works and the University of Dar es Salaam for the support they provided in this project. The role played by Mr. A Rwakajungute in the laboratory work is also highly appreciated.

\section{NOMENCLATURE}

\begin{tabular}{|c|l|r|}
\hline Item & \multicolumn{1}{|c|}{ Description } & \multicolumn{1}{c|}{ Unit } \\
\hline$U_{a}$ & Energy of deformation & $\mathrm{J} / \mathrm{m}^{2}$ \\
\hline$V$ & Volume & $\mathrm{m}^{3}$ \\
\hline$\dot{V}$ & Throughput & $\mathrm{m}^{3} / \mathrm{s}$ \\
\hline$S_{o}$ & Boundary surface energy & $\mathrm{J} / \mathrm{m}^{2}$ \\
\hline$g$ & Acceleration due to gravity & $\mathrm{m} / \mathrm{s}$ \\
\hline$\varphi$ & Voidage & - \\
\hline$I$ & Crack length & $\mathrm{m}$ \\
\hline
\end{tabular}




\begin{tabular}{|c|l|r|}
\hline$I_{\text {griff }}$ & Griffith length & $\mathrm{m}$ \\
\hline$\alpha$ & Angle of inclination & $\circ$ \\
\hline$\mu$ & Coefficient of friction & $\mathrm{Ns}^{2} / \mathrm{m}^{4}$ \\
\hline$h$ & The throw of the movable jaw & $\mathrm{m}$ \\
\hline$n_{G r}$ & Critical number of revolution & $\mathrm{s}^{-1}$ \\
\hline
\end{tabular}

\section{REFERENCE}

Griffith, A. A., (1921): The phenomena of rupture and flow in solids", Philos. Trans. Royal Society of London, Serial A, 221, 163/98.
Hoeffl, Karl, (1986): "Zerkleinerungs- und Klassiermaschinen", Springer-Verlag, Berlin

Rumpf, H., (1959): "Beanspruchungs-theorie der Prallzerkleinerung", technische Chemie, Verfahrenstechnik und Apparatenwesen, Verlag Chemie $\mathrm{GmbH}$, Weinheim, 31(1959)5 p. 323-337

Schoenert, K., (1991): "Advances in Comminution Fundamental and Impact in Technology", XVII International Mineral Processing Congress, Dresden. 